\title{
SOBRE O DESENVOLVIMENTO DA CATEGORIA CAPITAL PORTADOR DE JUROS ${ }^{1}$

\author{
RICARDO PEREIRA DE MELO ${ }^{2}$
}

RESUMO: O objetivo desse artigo é desenvolver a exposição dialética de Marx sobre o capital portador de juros e descobrir as potencialidades dessa categoria para compreender as relações fetichizadas do modo de produção capitalista. Para isso, pretende-se acompanhar a léxis de Marx sobre o desenvolvimento do capital e do juro que está presente nos capítulos XXI, XXII e XXIII da seção V do Livro III de O Capital. A seção V, como o próprio Engels afirma, foi a parte mais difícil de organizar e editar, pois muitos textos estavam inacabados e os capítulos não possuíam uma ordem expositiva clara. Dessa forma, o artigo busca organizar uma proposta de apresentação de leitura desses capítulos de O Capital.

PALAVRAS-CHAVE: Dialética, exposição, capital, juro, fetiche.

ABSTRACT: The objective of this article is to develop Marx's dialectical exposition on interest bearing capital and to discover the potentialities of this category to understand the fetishized relations of the capitalist mode of production. For this purpose, it is intended to follow Marx's lexis on the development of capital and interest that is presented in chapters XXI, XXII and XXIII of section V of Book III of Capital. The section V, as Engels himself states, was the most difficult part to organize and edit, since many texts were unfinished and the chapters did not have a clear expository order. Therefore, the article seeks to organize a proposal of presentation for the reading of these chapters of Capital.

KEYWORDS: Dialectic, exposition, capital, interest, fetish.

Marx deixou como legado a publicação e revisão do primeiro volume de $O$ Capital. A obra completa, segundo os planos de trabalho do autor, era para conter três livros: O Livro I: o processo de produção do capital; o Livro II: o processo de circulação do capital e; o Livro III: o processo global de produção capitalista. Antes de completar a sua obra máxima, Marx morre em 1883, deixando como herança intelectual uma série de textos inacabados do Livro II e III, sendo muitos deles ainda em formato de rascunhos.

A compilação desses textos não publicados ficou ao trabalho de Friedrich Engels, fiel amigo de Marx. Em 1885, acontece a publicação do Livro II e, em 1894, a edição do Livro

\footnotetext{
${ }^{1}$ Esse texto é uma versão modificada de parte de minha Tese de Doutorado desenvolvida no Programa de PósGraduação em Filosofia da Universidade Estadual de Campinas (UNICAMP) defendida em 2015, sob a orientação do Prof. Dr. Hector Benoit.

2 Professor do Programa de Mestrado Profissional em Filosofia (PROF-Filo) pela Universidade Federal de Mato Grosso do Sul (UFMS). Doutor em Filosofia pela Universidade Estadual de Campinas (UNICAMP). E-mail: ricardopdemelo@gmail.com.
} 
III de $O$ Capital. As principais controvérsias surgem, então, depois da publicação do Livro III, pois Engels relata no prefácio a dificuldade em terminar o trabalho e que teve de preencher as lacunas como um legítimo coautor. Esses tais acréscimos e disposição dos capítulos escritos por Engels seriam, segundo ele, a defesa da teoria do fiel amigo e a ordem expositiva dos textos era para que não houvesse dúvidas sobre a contribuição filosófica de Marx.

A partir desse debate, isto é, sobre "o que Marx realmente tinha dito", surgiu uma longa tradição entre Marx e o marxismo. Engels, fundador da $1^{\text {a }}$ Internacional e importante dirigente do Partido Social-Democrata da Alemanha (SPD), começa a publicar uma série de textos para debater o método dialético de Marx e a estrutura de $O$ Capital. Esse debate fez surgir diversas cisões no interior do marxismo e, o mais preocupante, o abandono da leitura do texto original e a sua literalidade.

Esses rascunhos originais de Marx nunca tiveram publicação completa na história pelo menos até 1980. A SPD, primeira detentora da herança intelectual de Marx, nunca demonstrou interesse em publicar os textos completos. A ascensão do stalinismo, assim como as duas guerras mundiais, fez com quem todos os textos preparatórios de $O$ Capital ficassem à margem de toda a discussão acadêmica e filosófica. A polêmica "lacuna" teórica de Marx na verdade é a história da ocultação ou, até mesmo falsificação, praticada pelos partidos socialistas por mais de um século.

Muito recentemente, a MEGA (Marx-Engels Gesamtausgabe) publicou todos os textos preparatórios de $O$ Capital, o que tornou possível uma série de novos debates sobre a estrutura de $O$ Capital e o método dialético de Marx. A partir dessa nova possibilidade de leitura, ao acompanhar a léxis do autor, estamos apenas começando um novo período de pesquisa sobre Marx e $O$ Capital.

O objetivo desse texto é acompanhar a léxis ${ }^{3}$ de Marx sobre o desenvolvimento da categoria capital portador de juros que está presente nos capítulos XXI, XXII e XXIII da seção V do Livro III de O Capital. A seção V, como o próprio Engels afirma, foi a parte mais difícil de organizar, pois muitos textos estavam inacabados e os capítulos não possuíam uma ordem expositiva clara. Em diversas partes, os adendos de Engels são longos parágrafos de comentários conjunturais, principalmente sobre as crises financeiras do capitalismo do final do século XIX e a concentração do capital causada pelo aumento do crédito ${ }^{4}$. Por ora, pretende-se

\footnotetext{
${ }^{3} \mathrm{O}$ termo Léxis empregado no texto deve-se aos diálogos com o professor Hector Benoit sobre a tradição dialética na história da filosofia. Ver BENOIT (2017).

${ }^{4}$ Deixamos para trabalhos futuros as críticas aos complementos literários de Engels na obra.
} 
discutir a exposição dialética de Marx sobre o capital a juros e descobrir as potencialidades dessa categoria tão importante.

\section{As determinações do juro em Marx}

O capital portador de juros consiste em uma nova forma de existência do capital na circulação. Segundo Marx, essa categoria é o capital sui generis, ou como ele mesmo diz, "o capital enquanto capital (Kapital als Kapital)". A mercadoria-capital ou capital portador de juros possui uma racionalidade própria e para se efetivar como movimento autônomo por meio do processo de troca, as relações jurídico-burguesas devem estar plenamente desenvolvidas para que possam refletir a vontade privada dos possuidores dessa mercadoria. Para efetivar seu movimento, as condições da circulação simples, isto é, o princípio da troca de equivalentes, devem estar presentes também na circulação do capital portador de juros, mesmo que, em contradição com a circulação capitalista em geral. Em nota, Marx cita Gilbart, para mostrar que o princípio das trocas iguais deve estar presente na circulação do capital portador de juros, então, que o "dinheiro emprestado com a intenção de fazer lucro com ele deva dar parte do lucro ao emprestador é um princípio evidente da justiça natural (Prinzip der natürlichen Gerechtigkeit)" (MARX, 1983a, p. 256; MARX, 1983b, p. 351).

Para tornar-se capital, o dinheiro paralisado nas mãos de seu proprietário precisa ser empregado em meios de produção e força de trabalho ou ser emprestado a um capitalista funcionante para render lucros. A partir do momento que o prestamista e também proprietário do dinheiro resolve emprestá-lo a outro capitalista, o dinheiro converte-se em capital. Destarte, o capital de empréstimo para tornar-se capital precisa encontrar sua forma adequada nas mãos do capitalista industrial ou comercial para ser empregado e adicionar mais dinheiro ${ }^{5}$.

Todo dinheiro é um meio potencial para produzir lucro, portanto pode-se afirmar que qualquer quantum de dinheiro consegue transforma-se em capital na esfera de produção, como capital industrial, ou na esfera de circulação, como capital comercial. Para render frutos, o dinheiro emprestado deve valorizar-se no processo global como capital, apropriando-se do trabalho excedente. Em seguida, depois de um tempo determinado, o capital de empréstimo retorna ao seu proprietário porque seu dinheiro rendeu "frutos" nas mãos do capitalista funcionante. A parte que retorna nas mãos do proprietário do dinheiro é denominada juro - uma

\footnotetext{
${ }^{5} \mathrm{Na}$ abertura da Seção V, intitulada Divisão do lucro em juro e lucro do empresário. Capital portador de juros, do Livro 3 de O Capital, Marx alerta que é importante não perder de vista que ele tratará dali em diante "a figura definitiva da taxa média [de lucro - RPM] (die fertige Gestalt der Durchschnittsrate)" analisada por ele nas seções anteriores (seção I a IV). Assim, se o capital é investido na esfera de produção ou se ele é investido na esfera comercial, o capital proporcionará o mesmo lucro médio.
} 
fração da mais-valia produzida pelo capital. O proprietário do capital emprestado dá ao seu dono o direito jurídico de abocanhar parte do lucro, ainda que este não seja produzido por ele.

Para compreender melhor a proposição do juro, supõe-se que: a) a taxa média anual de lucro $=20 \% ; b)$ o valor da máquina empregada $=100$ libras esterlinas; $\mathrm{c}$ ) a massa de lucro obtida após o processo de produção $=20$ libras esterlinas. Se uma pessoa qualquer possui 100 libras esterlinas, tem em suas mãos a capacidade de produzir 120 libras esterlinas (capital adiantado em máquinas + lucro). Agora, se ao invés de aplicar produtivamente, essa pessoa empresta as 100 libras esterlinas a outra, ao final de 1 ano deverá pagar "o valor de uso de sua função-capital (den Gebrauchswert ihrer Kapitalfunktion)" (MARX, 1983a, p. 256; MARX, 1983b, p. 351), função essa de produzir 20 libras esterlinas de lucro.

O lucro no final do processo produtivo é de 20 libras esterlinas, sendo agora que 5 libras deverão ser pagas ao proprietário inicial das 100 libras esterlinas, deduzido do lucro obtido. O juro, segundo Marx, nada mais é:

[...] que um nome particular, uma rubrica particular (eine besondre Rubrik) para uma parte do lucro, a qual o capital em funcionamento, em vez de pôr no próprio bolso, tem que pagar ao proprietário do capital (an den Eigner des Kapitals)"(MARX, 1983a, p. 256; MARX, 1983b, p. 351).

Neste momento expositivo, Marx desvela o "capital portador de juros em sua forma ordinária (Wir haben es hier mit dem zinstragenden Kapital in seiner gewöhnlichen Form zu tun)” (MARX, 1983a, p. 256; MARX, 1983b, p. 352), ou seja, o juro é a parte paga ao proprietário capitalista do dinheiro como parte da mais-valia produzida pelo capitalista funcionante.

Voltemos ao exemplo dado por Marx: se um capitalista A empresta 100 libras esterlinas ao capitalista B, B é o capitalista funcionante que emprega o dinheiro na forma de capital na compra de meios de produção (capital industrial) ou de mercadoria (capital mercantil). Ao final do processo, B produzirá 20 libras esterlinas de lucro, das quais pagará 5 libras esterlinas na forma de juro ao capitalista A. O ponto de partida é o dinheiro que A adianta a $\mathrm{B}^{6}$

Atentemo-nos ao movimento: $\mathrm{D}-\mathrm{D}-\mathrm{M}-\mathrm{D}$ ' - D'. Para realizar o movimento do capital industrial (D - M - D'), o capitalista B recebe o dinheiro de A e a transforma em capital para voltar em suas mãos (capitalistas A e B) na forma de D'. Assim, temos os valores: 100D

\footnotetext{
${ }^{6}$ Marx procura mostrar a circulação (movimento) do capital portador de juros ou a maneira peculiar que essa mercadoria-capital é emprestada. Não cabe aqui analisar, por enquanto, as formas particulares do capital portador de juros, como as letras de câmbio, ações e títulos da dívida pública.
} 
- 100D - 100M - 120D' - 105D'. A circulação do capital portador de juros, D - D', é 100D 105D', sendo $\Delta \mathrm{D}=5$. O capital emprestado pelo capitalista financeiro rendeu juros de 5 .

O movimento do capital portador de juros não constitui um momento da reprodução do capital ou mesmo da metamorfose de mercadorias. A primeira mudança de lugar de D - D expressa apenas sua transferência da pessoa A à B, "uma transferência que costuma realizar-se sob certas formas e garantias jurídicas" (MARX, 1983a, p. 257; MARX, 1983b, p. 353). O segundo momento constitui D' - D', corresponde a seu refluxo. O capitalista B transfere para A uma parte do lucro, como capital realizado, que corresponde ao juro. Contudo, segundo Marx, esse movimento configura-se da seguinte forma:

[...] B tem de entregar a A parte do lucro obtido com essa soma de capital sob o nome de juro, pois A só lhe deu o dinheiro como capital, isso é, como valor que não apenas se conserva em movimento, mas cria mais valia para seu proprietário. Permanece nas mãos de B apenas enquanto é capital funcionante (solange es fungierendes Kapital $i s t)$. E com seu refluxo $($ Rückflu $\beta)$ - no fim do prazo estipulado - deixa de funcionar como capital. Como capital não mais funcionante, tem de ser devolvido a $\mathrm{A}$, que não cessou de ser o proprietário jurídico do mesmo (der juristische Eigentümer desselben) (MARX, 1983a, p. 257; MARX, 1983b, p. 353).

No primeiro movimento $\mathrm{D}-\mathrm{D}$ não expressa qualquer metamorfose do valorcapital, mas apenas mudança de mãos. O mesmo ocorre com o movimento D' - D'. Enquanto no primeiro movimento o prestamista cede seu capital emprestável ao prestatário, no segundo movimento acontece o inverso. Ambas as transações são transações meramente jurídicas. O que ocorre é unicamente a introdução de duas pessoas diferentes no processo de reprodução do capital, uma aparece como proprietária do capital e a outra como capitalista funcionante, repartindo a massa de mais-valia criada pelo capital entre dois capitalistas distintos. Para Marx:

O capitalista existe em dois níveis - o jurídico e o econômico. Por isso, o capital como propriedade reflui também para o capitalista jurídico, príncipe de um consórcio morganático (Der Kapitalist existiert doppelt. Juristisch und ökonomisch. Als Eigentum kehrt es daher auch zu dem juristischen Kapitalisten, [dem] left handed Seim, zurück) (MARX, 1985, p. 1499; MARX, 1968, p. 450).

O capital monetário emprestável realiza um duplo retorno: primeiro, ele retorna nas mãos do capitalista funcionante como capital-dinheiro; em seguida, parte do capital produzido é transferida para o capitalista financeiro como juro. Ambos são figuras do capital na forma de dinheiro, mas distinguem-se pelo modo que entram no processo de reprodução social.

Para o capitalista funcionante, o capital emprestado não the pertence no ato de cessão e nem de retorno. A passagem do capital no processo de reprodução não converte o capital emprestável em propriedade do capitalista funcionante. Este, por sua vez, introduz o capital no ciclo reprodutivo para gerar mais capital. Os atos de empréstimo e retorno do capital 
emprestável são movimentos puramente arbitrários e garantidos por contratos jurídicos diversos, sem ter relação com o ciclo reprodutivo do capital.

O movimento característico do capital portador de juros é o empréstimo de determinado quantum de capital por tempo determinado e, em seguida, a devolução desse capital agora acrescido de juros, como parte da mais-valia produzida fora desse circuito. Podese afirmar que todo o ciclo reprodutivo do capital é uma operação que transcende as transações jurídicas da mercadoria-capital, como se o juro (capital) tivesse surgido de si mesmo. Todo o processo de extração de mais-valia fica invisível e desaparecem as mediações da fórmula geral D-D-M-D'-D', aparecendo apenas seus extremos D - D'.

O ciclo D-M(MP+FT)...P...M'-D' aparece fora do circuito acima descrito. Deste modo, a circulação do capital portador de juros ou a mercadoria-capital reduz-se, aparentemente, ao movimento D - D', sem relação direta com a produção e circulação do valorcapital. O juro aparece completamente desprendido de quaisquer fatores econômicos e somente ligado a fatores jurídicos. É por isso, que o juro é uma forma que encobre as relações capitalistas:

Nela se extingue toda mediação, completa-se a configuração fetichista do capital e a idéia do fetiche-capital (In dieser Form ist alle Vermittlung ausgelöscht, und die Fetischgestalt des Kapitals wie die Vorstellung von dem Kapitalfetisch fertig). Essa configuração tem de produzir-se por se dissociar a dominação jurídica do capital de sua dominação econômica e por afluir para o capital em si de todo separado (sich trennt) do processo de produção, ou para o proprietário do capital, uma parte do lucro, sob o nome de juro [...] A forma ininteligível encontrada na superfície e donde por isso partimos em nossa análise, de novo achamos como o resultado do processo em que a figura do capital, de maneira progressiva, cada vez se aliena e se desliga de sua natureza intrínseca (MARX, 1985, p. 1502 e 1506; MARX, 1968, p. 454 e 458-459).

A fórmula D - M - D' é reduzida apenas aos seus extremos D - D', aparecendo como se o dinheiro gerasse mais dinheiro a partir de si mesmo. A fórmula aparente do capital portador de juros, D - D', obscurece o movimento geral do capital, "numa súmula absurda (ein sinnloses Resume)" (MARX, 1985, p. 1495; MARX, 1968, p. 446). As formas do valor-capital, quando aparecem na circulação, mistificam as fontes originárias dos rendimentos e confunde as diferenças qualitativas do movimento geral do capital. Entretanto, "de todas essas formas, porém o fetiche mais completo (vollständigste Fetisch) é o capital portador de juros" (MARX, 1985, p. 1495; MARX, 1968, p. 445).

Com a concretização da circulação financeira do capital, a mercadoria-capital se efetiva na circulação, subordinando a circulação simples e real pela circulação creditícia. Assim, o juro aparece como uma qualidade intrínseca ao capital, mistificando e escondendo todas as relações capitalistas de produção. É por isso que Marx classifica a aparência da 
circulação D - D' como o mais alto grau de mistificação. O movimento D - D' ou a circulação do capital portador de juros converte-se em um movimento autônomo do ciclo real do capital. 'Em D - D' temos a forma do capital vazia de conceito, a inversão (die Verkehrung) e a reificação (Versachlichung) das relações de produção levadas ao extremo (in der höchsten Potenz)" (MARX, 1985, p. 1502; MARX, 1968, p. 454).

\section{A relação fetichizada entre juro e ganho empresarial}

Na abertura do capítulo XXIII do Livro 3 de $O$ Capital, Marx novamente reafirma - assim como durante todo o capítulo - que o juro é apenas parte do lucro. O juro é a parte da mais-valia empregada pelo capitalista funcionante (industrial e comercial) que não usa capital próprio e, por isso, precisa pagar ao prestamista parte do valor produzido pelo dinheiro emprestado. A categoria juro apenas é criada quando existe a separação entre duas espécies de capitalistas juridicamente opostas: capitalista monetário e capitalista funcionante.

Da divisão do lucro médio em juro e lucro empresarial emerge um duplo movimento do fluxo da mais-valia produzida. Dá-se que o mesmo capital produzido na esfera de produção flui para o capitalista monetário na forma de juro ou rendimento de propriedade e flui para o capitalista funcionante na forma de lucro empresarial.

Dessa maneira, a fórmula geral do capital a juros, D-M...P...M'-D', não aparece e todo o movimento fica oculto. É como se o dinheiro produzisse mais dinheiro sem precisar passar pelo processo de produção. A fórmula aparente do capital a juro, D - D', serve apenas para mistificar a origem e a circulação da mais-valia ${ }^{7}$.

Para o capitalista monetário interessa que seu capital lhe proporcione juros. Enquanto o capital se encontrar em suas mãos, ele não proporciona juros e não atua como capital. O capital fora do processo reprodutivo é apenas dinheiro latente. Imediatamente, para o capitalista financeiro, interessa-lhe emprestar dinheiro "por tempo perpétuo". O dinheiro imobilizado precisa ser emprestado para que esse atue como capital monetário. Aqui a "única diferença que ainda resta é a óbvia, de que um é proprietário de seu capital e o outro não" (MARX, 1983a, p. 278; MARX, 1983b, p. 385). Essa forma perpétua da categoria juro tornase a base - irracional e fetichizada - do modo de produção capitalista.

Agora, sabendo-se da divisão quantitativa entre juro e lucro, como entender essa divisão do ponto de vista qualitativo? $\mathrm{Ou}$,

\footnotetext{
${ }^{7}$ A fórmula D - D' para a visão do banqueiro prático é como se seu dinheiro multiplicasse infinitamente e tudo isso fosse fruto do próprio capital.
} 
Em outras palavras, como explicar que também o capitalista que emprega apenas capital próprio e nenhum capital emprestado classifique parte de seu lucro bruto na categoria particular de juro e, como tal, a calcule separadamente? E que portanto, ainda mais, todo capital, emprestado ou não, é distinguido como portador de juros em si mesmo [...] (MARX, 1983a, p. 278; MARX, 1983b, p. 385).

Para entender a transformação quantitativa em qualitativa, Marx se detém "mais algum tempo no verdadeiro ponto de partida da formação do juro", ou seja, na divisão quantitativa entre o capitalista financeiro e o capitalista industrial (mercantil) ${ }^{8}$. Para o capitalista industrial ou comercial que trabalha com capital emprestado, ele não obtém (realmente) no final do processo o lucro, mas sim o lucro menos o juro, "a parte do lucro que lhe resta depois de pagar o juro". Assim, temos a denominação dada por Marx utilizando-se da expressão alemã Unternehmergewinn ou ganho empresarial. O ganho empresarial é, portanto, a parte restante do lucro bruto, que resta depois do pagamento do juro.

A funcionalidade com a qual a repartição do lucro bruto se transforma nas mãos do capitalista funcionante, modifica qualitativamente a relação. O ganho empresarial, ao invés de aparecer como a parte quantitativa da mais-valia, aparece como uma remuneração justa pela sua funcionalidade enquanto um capitalista específico. Assim, o lucro industrial (como parte do lucro bruto) "aparece agora como ganho empresarial oriundo exclusivamente das operações ou funções que ele efetua com o capital no processo de reprodução, especialmente, pois, das funções que como empresário ele exerce na indústria ou no comércio" (MARX, 1983a, p. 280; MARX, 1983b, p. 387).

Enquanto isso, o juro ou a parte quantitativa do lucro bruto ou da mais-valia produzida a ser paga ao capitalista financeiro aparece agora "como mero fruto da propriedade do capital, do capital em si”. Para Marx, o processo de mistificação das relações capitalistas avança.

\begin{abstract}
Essa separação qualitativa entre as duas partes do lucro bruto, pela qual o juro é fruto do capital em si, da propriedade do capital, abstraído o processo de produção, e o ganho empresarial é fruto do capital processante, que atua no processo de produção, e portanto do papel ativo que o aplicador do capital desempenha no processo de reprodução - essa separação qualitativa não é de modo algum concepção meramente subjetiva do capitalista monetário aqui e do capitalista industrial lá. Ele repousa sobre um fato objetivo, pois o juro flui para o capitalista monetário, o prestamista, que é mero proprietário do capital, que representa, portanto, a mera propriedade do capital antes e fora do processo de produção; e o ganho empresarial flui para o capitalista meramente funcionante, que é não proprietário do capital (MARX, 1983a, p. 280; MARX, 1983b, p. 387-388).
\end{abstract}

\footnotetext{
${ }^{8}$ Essa transformação quantitativa em qualitativa não acontece em todos os negócios da burguesia. Marx cita duas exceções: a) quando os capitalistas industriais se associam para operar um negócio e distribuem então entre si o lucro de acordo com convenções juridicamente estabelecidas; b) quando o negócio é operado individualmente, não existindo dessa forma a divisão entre o lucro individual e o lucro da companhia (sócios).
} 
Essa relação oculta a origem da mais-valia e a luta de classes entre os proprietários dos meios de produção e os proprietários da força de trabalho. Aqui o conflito aparece mistificado por uma repartição quantitativa e qualitativa entre dois capitalistas juridicamente diferentes. De um lado, o ganho empresarial aparece como mero fruto do que o capitalista ativo exerce no processo de reprodução do capital. Do outro lado, o juro como mero fruto da propriedade do capital:

E essa ossificação e autonomização (Und diese Verknöcherung und Verselbständigung) das duas partes do lucro bruto contra si, como se originassem de duas fontes essencialmente diversas, tem de se consolidar para classe capitalista inteira e para o capital global (die gesamte Kapitalistenklasse und für das Gesamtkapital festsetzen) (MARX, 1983a, p. 280; MARX, 1983b, p. 388 - negritos RPM).

Se o capital é emprestado ou não, o que importa (ideologicamente) é mostrar que as partes destinadas ao ganho empresarial e ao juro são determinadas por leis especificas e independentes entre si. "Assim, para essa divisão, enquanto qualitativa, torna-se indiferente se o capitalista tem realmente de repartir com outro ou não". A repartição do lucro global em juro e ganho empresarial é uma determinação social necessária do capital.

$\mathrm{Na}$ “imaginação popular”, segundo Marx, o capital portador de juros/capital monetário emprestável é capital como tal, "capital par excellence”. É importante destacar aqui, independente se o capital emprestável será utilizado como capital funcionante ou para o consumo, para Marx consolida a concepção da autonomia do capital a juros. Por isso a confusão dessa forma entre os economistas ingleses.

Se o capitalista trabalha com capital próprio ou emprestado, em nada altera a função da classe dos capitalistas monetários. Qualitativamente, o juro é mais-valia que a mera propriedade do capital proporciona, embora seu proprietário fique fora do processo. Quantitativamente, a parte do lucro que constitui o juro não aparece relacionada com o capital industrial e comercial como tal, mas com o capital monetário.

Se uma parte grande dos capitalistas quisesse transformar seu capital em capital monetário, a consequência seria uma imensa desvalorização do capital monetário e uma imensa queda da taxa de juros. Para Marx, vários capitalistas monetários se veriam forçados a voltar a serem capitalistas industriais, não pela necessidade do consumo, mas pela necessidade intensa de obter mais dinheiro.

A mistificação que acontece no modo de produção capitalista faz com que o juro e o ganho empresarial apareçam como partes não relacionadas à extração de mais-valia da classe trabalhadora e sim como rubricas ou números diversos. Na forma juros, segundo Marx, a 
antítese entre o capital a juros e o trabalho assalariado está completamente apagada. Assim, o capital portador de juros se apresenta como antítese do capital funcionante.

O capital portador de juros é o capital enquanto propriedade em confronto com o capital enquanto função. Mas, à medida que o capital não funciona, ele não explora os trabalhadores nem entra em antagonismo com o trabalho (MARX, 1983a, p. 283; MARX, 1983b, p. 392 - grifos do próprio Marx).

Assim acontece também com o ganho empresarial. O ganho empresarial apresentase como antítese do capitalista monetário. Todas as contradições são totalmente fetichizadas agora. Dessa função, enquanto capitalista industrial, o lucro se apresenta agora (descontado os juros aos prestamistas) como ganho, ou melhor, como um salário mesmo, como salário de superintendência. Esse salário é mais alto que do trabalhador, "porque é trabalho mais complicado" e, "porque ele mesmo se paga o salário".

Com o desenvolvimento da categoria "ganho empresarial", o capitalista industrial aparece não como proprietário do capital, mas como funcionário, como trabalhador. Assim como o trabalhador, o capitalista funcionante recebe um salário pelo trabalho que realizou, de "modo que o trabalho de explorar é tanto trabalho quanto o trabalho que é explorado".

Para o trabalhador, tanto faz se o capitalista industrial precisa dividir uma parte maior ou menor da mais-valia com os prestamistas. O juro é uma relação entre dois capitalistas e não entre capitalista e trabalhador. A forma social do juro expressa uma aparente neutralidade ao trabalho não-pago.

Os motivos da repartição do lucro entre duas espécies de capitalista transformam-se assim sub-repticiamente nos motivos da existência do lucro, da mais-valia a repartir que o capital como tal, abstraindo qualquer divisão posterior, retira do processo de reprodução (MARX, 1983a, p. 284; MARX, 1983b, p. 398).

O ganho empresarial torna-se um ordenado de dirigente naqueles ramos de negócios maiores que permitem a contratação de um trabalhador com salário diferenciado ${ }^{9}$. As empresas com ações tendem a multiplicar esse tipo de trabalho. Com o desenvolvimento das sociedades por ações, fica explícito o papel dos managers.

[...] com base na produção capitalista desenvolveu-se nas empresas por ações novo embuste com o salário de administração (ein neuer Schwindel mit dem Verwaltungslohn), surgindo ao lado e acima do dirigente real certo número de conselhos de administração e fiscais, para os quais, na realidade, administração e fiscalização servem de mero pretexto para espoliarem os acionistas e se enriquecerem (MARX, 1983a, p. 290; MARX, 1983b, p. 403).

\footnotetext{
${ }^{9}$ Para Marx, esse trabalho de superintendente existe em todos os modos de produção, quanto maior a antítese mais importante é o papel do superintendente. Tanto o trabalhador assalariado quanto o escravo antigo precisam ter um senhor para fazê-los trabalhar e para governá-los.
} 
Assim, o salário de direção assume a forma de trabalho mais qualificado e, por isso, a remuneração efetuada é maior. No caso, os "managers" possuem os melhores salários na organização social capitalista, não porquê são os mais qualificados, mas por exercer o controle da exploração da força de trabalho. Torna-se inútil o trabalho de superintendente ser exercido pelo próprio capitalista ${ }^{10}$.

Sua função como capitalista fica totalmente apagada e fetichizada neste processo. Assim, se perde de vista, que tanto o juro quanto o ganho empresarial são frutos da mais-valia. A relação dada entre o capitalista industrial e monetário não está colocada em nenhuma relação com o trabalho não-pago. Todas as contradições são ocultadas.

A alienação da relação capital na forma de capital portador de juros atinge sua forma mais alienada e mais fetichista. A fórmula D - D', ou seja, dinheiro que gera mais dinheiro, apresenta-se na superfície da sociedade capitalista como valor que valoriza-se por si mesmo, sem o processo que medeia os dois extremos. Com o desenvolvimento da categoria capital portador de juros, ocultam-se as relações entre os donos dos meios de produção e a classe trabalhadora. A separação do lucro médio em juro e ganho empresarial desaparece (ou mistifica) a relação contraditória entre capital e trabalho. Na forma capital portador de juros, D - D', “o capital aparece como fonte misteriosa, autocriadora do juro, de seu próprio incremento".

A origem da mais-valia é completamente apagada na fórmula do capital portador de juros, "condensada nesta fórmula sem sentido", e desaparece a origem do D' (= D + d). Assim, como na seção I do Livro 3, Marx mostra como a categoria preço de mercado individual $(=$ custo + lucro $)$, mistifica a origem da mais-valia, ao transformar as diferenças entre capital constante e capital variável desprezíveis em relação à categoria "custo", nestes três primeiros capítulos da seção V do Livro 3, acontece um novo salto do processo de alienação/mistificação das relações capitalistas:

$\mathrm{Na}$ forma capital portador de juros, portanto, esse fetiche automático está elaborado em sua pureza, valor que valoriza a si mesmo, dinheiro que gera dinheiro, e ele não traz nenhuma marca de seu nascimento [...] A relação social está consumada como relação de uma coisa, do dinheiro, consigo mesmo [...] O capital recebe na sua forma pura de fetiche, D - D' como sujeito [...] Em D - D' temos a forma irracional do capital, a inversão e reificação das relações de produção em sua potência mais elevada: a figura portadora de juros, a figura simples do capital, na qual este é pressuposto de seu próprio processo de reprodução [...] a mistificação do capital em a forma mais crua (MAX, 1983a, p. 294; MARX, 1983b, p. 405).

\footnotetext{
${ }^{10}$ Em momentos de crise, vários ex-industriais transformam-se em manager das fábricas de seus credores.
} 
O capital portador de juros é o capital por completo, "pronto e acabado". O capital portador de juros unifica os processos de produção e circulação. A fórmula do capital portador de juros é para Marx um grande petisco as formulações dos economistas vulgares e apologistas do capital, pois sob essa forma a fonte do lucro não aparece e o resultado da produção capitalista adquire existência autônoma. O trabalhador é colocado em segundo plano. Agora o capitalista estando dormindo ou acordado, seu capital acresce-lhe mais capital na juros:

[...] enquanto o juro é apenas parte do lucro, isto é, da mais-valia que o capitalista funcionante extorque do trabalhador, o juro aparece agora, ao contrário, como o fruto próprio do capital, como o original, e o lucro agora na forma de ganho empresarial, como mero acessório aditivo que lhe advém no processo de reprodução. Aqui a figura fetichista do capital e a concepção do fetiche-capital está acabada (Hier ist die Fetischgestalt des Kapitals und die Vorstellung vom Kapitalfetisch fertig) (MARX, 1983a, p. 294; MARX, 1983b, p. 405).

Marx ilustra uma passagem sobre o fundo de amortização da dívida pública proposta pelo autor Pitt para demonstrar, segundo ele, "uma bela introdução teórica à dívida pública inglesa [...] um Estado nunca necessita encontrar-se em dificuldades; pois com as menores poupanças ele pode pagar a maior dívida em tempo tão curto quanto possa requerer seu interesse" (MARX, 1983a, p. 296; MARX, 1983b, p. 408-409 - Pitt citado por Marx).

A acumulação da dívida pública é "solucionada" pelas leis do fundo de amortização de Pitt propostas na Câmara dos Comuns na Inglaterra. “[...] empréstimos, empréstimos para pagar empréstimos." Assim, toda a riqueza na forma de imposto é agora utilizada para o pagamento de juros sobre capital:

A concepção do capital como valor que reproduz a si mesmo e se multiplica na reprodução, em virtude de sua propriedade inata de ser um valor que dura e cresce eternamente - portanto, por força da qualidade oculta dos escolásticos - levou às fabulosas idéias do Dr. Price, que deixam muito para trás as fantasias dos alquimistas (MARX, 1983a, p. 295-296; MARX, 1983b, p. 408).

Pitt leva muito a sério a ideia da mistificação do capital portador de juros. Para pagar a dívida pública e o mistério dos juros compostos sobre o capital, não existe melhor forma do que acumular fundos para tão realização, ou seja, "tributar o povo", e assim, como num passe de mágica, sumir com a dívida pública. Na crise, como afirma Marx, o movimento do capital portador de juros aparece em sua verdadeira essência de ser "a mera forma vazia dessa metamorfose (nur die inhaltslose Form derselben)" (MARX, 1985, p. 1498; MARX, 1968, p. 450). 


\section{REFERÊNCIAS BIBLIOGRÁFICAS}

BENOIT, Hector. A Odisseia de Platão: as aventuras e desventuras da dialética. São Paulo: Annablume, 2017.

MARX, Karl. Theorien über den Mehrwert. Dritter Teil. MARX, Karl; ENGELS, Friedrich: Werke (Band 26.3). Berlin: Dietz Verlag, 1968.

O Capital. Volume 3: O processo global da produção do capital. Tomo 1. Trad. Regis Barbosa e Flávio R. Kothe. São Paulo: Abril Cultural, 1983a.

Das Kapital. MARX, Karl; ENGELS, Friedrich: Werke (Band 25). Berlin: Dietz Verlag, 1983b.

Teorias da mais-valia: história crítica do pensamento econômico. Volume 3. Trad. Reginaldo Sant'anna. São Paulo: Difel, 1985. 